\title{
FAKTOR RISIKO LOW BACK PAIN PADA MAHASISWA JURUSAN ORTOTIK PROSTETIK POLITEKNIK KESEHATAN SURAKARTA
}

\author{
Martina Wulandari, Dwi Setyawan, Alfan Zubaidi \\ Kementerian Kesehatan Politeknik Kesehatan Surakarta Jurusan Ortotik Prostetik
}

\begin{abstract}
Risk factors, Low Back Pain, Prosthetics and Orthotics Students of Health Polytechnic of Surakarta. Low Back Pain (LBP) or lower back pain is a common health problem that found in many people, not only in older people but also in younger nowadays. Low Back Pain associated with many kind of conditions and also risk factors. The etiology of LBP is widely accepted to be multi-factorial. The objectives of this study were to determine the risk factors causing LBP on Prosthetics and Orthotics students of Health Polytechnic of Surakarta. The study is cross sectional design used a questionnaire instrument to all Prosthetics and Orthotics students. Data analysis was performed by Chi square. The results showed that the prevalence of LBP after being Prosthetics and Orthotics students of Health Polytechnic of Surakarta is 32,2\%. Risk factors associated with Low Back Pain were exercise ( $p$ value 0,033), daily time spend standing ( $p$ value 0,046), lifting ( $p$ value 0,027) and perceived stress ( $p$ value 0,008). Gender, body mass index and daily time spend sitting were not associate with Low Back Pain.
\end{abstract}

Keywords: Risk factors, Low Back Pain, Prosthetics and Orthotics Students of Health Polytechnic of Surakarta

\begin{abstract}
Abstrak : Faktor risiko, Low Back Pain, Mahasiswa Jurusan Ortotik Prostetik Politeknik Kesehatan Surakarta. Low Back Pain (LBP) atau nyeri punggung bawah adalah masalah kesehatan yang dapat dialami oleh siapa saja, tidak hanya pada orang berusia lanjut tetapi juga pada remaja saat ini. Low Back Pain berhubungan dengan berbagai kondisi dan juga faktor risiko. Etiologi LBP telah diketahui secara luas terdiri dari banyak faktor. Tujuan dalam penelitian ini adalah untuk mengetahui faktor risiko yang berhubungan dengan terjadinya Low Back Pain pada mahasiswa jurusan Ortotik Prostetik Politeknik Kesehatan Surakarta. Metode penelitian yang digunakan adalah metode cross sectional dengan instrumen kuesioner yang dibagikan kepada seluruh mahasiswa jurusan Ortotik Prostetik Politeknik Kesehatan Surakarta. Analisis data dilakukan dengan uji Chi square. Hasil penelitian menunjukkan bahwa prevalensi Low Back Pain yang timbul setelah menjadi mahasiswa jurusan Ortotik Prostetik Politeknik Kesehatan Surakarta adalah 32,2\%. Faktor risiko yang berhubungan adalah kebiasaan olahraga ( $\mathrm{p}$ value 0,033), kebiasaan berdiri ( $\mathrm{p}$ value 0,046$)$, kebiasaan mengangkat ( $\mathrm{p}$ value 0,027) dan stress ( $\mathrm{p}$ value 0,008). Sedangkan faktor risiko yang tidak berhubungan secara signifikan yaitu jenis kelamin, indeks massa tubuh dan kebiasaan duduk.
\end{abstract}

Kata Kunci: Faktor risiko, Low Back Pain, Mahasiswa Jurusan Ortotik Prostetik Politeknik Kesehatan Surakarta 


\section{PENDAHULUAN}

Low Back Pain (LBP) atau nyeri punggung bawah merupakan suatu penyakit yang sering dijumpai di masyarakat. LBP sering menjadi penyebab seseorang merasakan penurunan kemampuan pada aktivitas fungsional sehari-hari.

Di Inggris dan Amerika Serikat kejadian nyeri punggung terutama nyeri punggung bagian bawah telah mencapai proporsi endemik. Survei yang telah dilakukan melaporkan bahwa 17,3 juta orang di Inggris pernah mengalami nyeri punggung. Sedangkan diperkirakan prevalensi Low Back Pain di Indonesia bervariasi antara 7,6\%-37\%.

Kebanyakan kasus LBP terjadi dengan adanya pemicu seperti kerja berlebihan, penggunaan kekuatan otot berlebihan, ketegangan otot, cedera otot, ligamen, maupun diskus yang menyokong tulang belakang. Namun, keadaan ini dapat juga disebabkan oleh keadaan nonmekanik seperti peradangan pada ankilosing spondilitis dan infeksi, neoplasma, dan osteoporosis.

Penyebab tersering LBP adalah pembebanan atau distorsi mekanik seperti mengangkat barang. Terutama pada orang dengan otot dinding perut atau pinggang dan punggung yang kurang kuat. Nyeri terjadi pada gerakan ke depan, ke lumbosakral dengan atau tanpa nyeri alih ke region gluteal.

Posisi duduk yang terlalu lama, kegiatan mengangkat benda yang cukup berat yang dilakukan mahasiswa saat proses pembelajaran memungkinkan menjadi penyebab timbulnya LBP.

Tujuan dalam penelitian ini adalah untuk mengetahui faktor risiko yang berhubungan dengan LBP pada mahasiswa jurusan Ortotik Prostetik
Politeknik Kesehatan Surakarta sehingga dapat ditemukan solusi alternatif mengenai tidakan pencegahan terhadap risiko terjadinya LBP.

\section{METODE PENELITIAN}

Penelitian ini merupakan penelitian awal yang menggunakan metode penelitian deskriptif dengan rancangan penelitian cross sectional. Subjek penelitian merupakan seluruh mahasiswa jurusan Ortotik Prostetik Politeknik Kesehatan Surakarta angkatan 2012-2015.

Instrumen penelitian berupa timbangan injak untuk mengukur berat badan (merk Camry), alat pengukur tinggi badan (sature meter) dan kuesioner. Kuesioner yang digunakan merupakan modifikasi dari kuesioner penelitian Naude (2008) mengenai faktor yang berhubungan dengan kejadian Low Back Pain pada pekerja rumah sakit yang terdiri dari 18 item pertanyaan.

Pengisian kuesioner dan pengukuran dilakukan oleh seluruh mahasiswa jurusan Ortotik Prostetik Politeknik Kesehatan Surakarta setelah mengisi informed consent dan setelah mendapat penjelasan mengenai tujuan dan manfaat dari penelitian yang dilakukan.

Data yang diperoleh dicatat dalam formulir penelitian, kemudian dilakukan editing, coding, data entry, data cleaning dan analisis statistika. Analisis statistika untuk mencari hubungan pada data kategorik dengan data kategorik dalam sampel besar adalah menggunakan uji $C h i$ square. Kriteria kemaknaan yang digunakan apabila nilai $\mathrm{p} \leq 0,05$ adalah signifikan dan apabila nilai $\mathrm{p}>0,05$ maka tidak bermakna secara signifikan. Analisis data dilakukan dengan program Statistical 
Product and Service Solution (SPSS) versi 22.0 for Windows.

\section{HASIL PENELITIAN}

Subjek yang tidak memenuhi kriteria inklusi sebanyak 56 mahasiswa, sedangkan subjek penelitian yang memenuhi kriteria inklusi sebanyak 180 mahasiswa (Tabel 1).

Variabel yang diteliti yaitu faktor individu yang terdiri dari jenis kelamin, indeks massa tubuh dan olahraga, dan faktor okupasi yang terdiri dari duduk, berdiri, mengangkat yang menjadi salah satu kegiatan manual handling dan faktor stress. Variabel yang berhubungan adalah kebiasaan olahraga $(\mathrm{p}=0,033)$, kebiasaan berdiri $(\mathrm{p}=0,046)$, kebiasaan mengangkat $(\mathrm{p}=0,027) \quad$ dan stress $(\mathrm{p}=0,008)$. Sedangkan variabel yang tidak berhubungan secara signifikan yaitu jenis kelamin ( $p$ value 0,076), indeks massa tubuh (IMT) $(\mathrm{p}=0,458)$ dan kebiasaan duduk (p-0,280) (Tabel 2).

Tabel 1

\begin{tabular}{cc}
\multicolumn{3}{c}{ Tabel } \\
Karakteristik Responden \\
\hline Variabel & Total $(\%)$ \\
& n-180 \\
\hline & $145(80,6)$ \\
& $32(17,8)$ \\
& $3(1,7)$ \\
Usia(tahun) & $71(39,4)$ \\
18-20 & $109(60,6)$ \\
21-23 & \\
>23 & $74(41,1)$ \\
Jenis kelamin & $106(58,9)$ \\
Laki-laki & \\
Perempuan & $89(49,4)$ \\
Jenjang pendidikan & $52(28,9)$ \\
D III & $20(11,1)$ \\
D IV & $19(10,6)$ \\
Masa studi (semester) & \\
II & $46(25,6)$ \\
IV & $111(61,7)$ \\
VI & $23(12,8)$ \\
VIII & \\
IMT (kg/m²) & \\
Underweight & \\
Normal & \\
Overweight & \\
\hline
\end{tabular}

\section{PEMBAHASAN}

Kriteria diagnosis Low Back Pain adalah adanya salah satu keluhan nyeri, pegal, panas atau kram pada punggung bawah yang bersifat setempat tanpa disertai dengan kelainan neurologis dan pada pemeriksaan fisik neurologi ditemukan adanya nyeri tekan dan atau nyeri gerak. Prevalensi Low Back Pain yang timbul setelah menjadi mahasiswa jurusan Ortotik Prostetik Politeknik Kesehatan Surakarta adalah 32,2\%, hal ini disebabkan oleh adanya beberapa faktor risiko yang terdiri dari faktor risiko individu dan faktor okupasi. Faktor risiko individu terdiri dari jenis kelamin, indeks massa tubuh (IMT) dan kebiasaan olahraga sedangkan faktor okupasi berupa lama duduk, lama berdiri, kebiasaan mengangkat dan tingkat stress. Faktor risiko pada penelitian ini yang paling meningkatkan risiko Low Back Pain adalah faktor kebiasaan olahraga, lama berdiri, kebiasaan mengangkat, dan tingkat stress.

Pada penelitian ini didapatkan hasil uji statistik tidak terdapat hubungan bermakna antara jenis kelamin dengan Low Back Pain (p value $=0,076$ ). Pria dan wanita berbeda dalam kemampuan fisiknya dan kekuatan kerja ototnya. Perbedaan tersebut dapat dilihat melalui ukuran tubuh dan kekuatan otot dari wanita relatif kurang jika dibandingkan pria. Hal ini dibuktikan dengan jumlah keluhan nyeri punggung terbanyak pada jenis kelamin perempuan yaitu sebanyak 40 mahasiswa, dibandingkan laki-lakinya yang hanya 18 mahasiswa yang pernah mengalami LBP.

Pada penelitian ini indeks massa tubuh (IMT) tidak berhubungan secara signifikan dengan kejadian LBP pada mahasiswa dengan nilai $\mathrm{p} 0,458$. 
Tidak adanya hubungan antara obesitas dengan LBP kemungkinan disebabkan karena sebaran data yang tidak merata antara keluhan Low Back Pain dengan obesitas. Jelas terlihat bahwa jumlah responden yang overweight/obesitas dan mengeluh Low Back Pain lebih sedikit daripada responden yang normal dan mengeluh Low Back Pain.

Tabel 2.

Faktor Risiko Low Back Pain

\begin{tabular}{|c|c|c|c|}
\hline Faktor Risiko & $\begin{array}{c}\text { LBP } \\
\text { (n) }\end{array}$ & $\begin{array}{c}\text { Tidak } \\
\text { LBP (n) }\end{array}$ & Nilai p \\
\hline \multicolumn{4}{|l|}{ Faktor individu } \\
\hline \multicolumn{4}{|l|}{ Jenis kelamin } \\
\hline Laki-laki & 18 & 53 & 0,076 \\
\hline Perempuan & 40 & 69 & \\
\hline \multicolumn{4}{|l|}{ IMT } \\
\hline Underweight & 17 & 29 & \\
\hline Normal & 32 & 79 & 0,458 \\
\hline Overweight & 9 & 14 & \\
\hline \multicolumn{4}{|l|}{ Olahraga } \\
\hline Iya & 12 & 43 & 0,033 \\
\hline Tidak & 46 & 79 & \\
\hline \multicolumn{4}{|l|}{ Faktor okupasi } \\
\hline \multicolumn{4}{|l|}{ Duduk (jam/hari) } \\
\hline \multicolumn{4}{|l|}{$2-4$} \\
\hline $5-6$ & 22 & 34 & \\
\hline$>6$ & 31 & 70 & 0,280 \\
\hline Berdiri (jam/hari) & 5 & 18 & \\
\hline \multicolumn{4}{|l|}{$0-1$} \\
\hline $2-4$ & 27 & 62 & \\
\hline $5-6$ & 21 & 53 & 0,046 \\
\hline \multicolumn{4}{|l|}{ Tidak pernah } \\
\hline Kadang-kadang & 12 & 18 & \\
\hline Sering & 35 & 95 & 0,027 \\
\hline Stress & 11 & 9 & \\
\hline \multicolumn{4}{|l|}{ Tidak pernah } \\
\hline Kadang-kadang & 3 & 25 & \\
\hline Sering & 45 & 88 & 0,008 \\
\hline & 10 & 9 & \\
\hline
\end{tabular}

IMT yang baik mungkin juga berkaitan dengan anggapan kekuatan otot yang lebih baik. Responden yang mempunyai badan besar, mungkin mampu mengangkat barang yang lebih berat. Bila hal ini dilakukan hanya sesekali dan dengan cara yang benar maka tidak akan terjadi regangan otot, namun bila mengangkat dilakukan dengan cara yang salah maka risiko cedera otot menjadi besar.

Pada penelitian ini, salah satu faktor risiko yang secara statistika signifikan berkontribusi terhadap timbulnya Low Back Pain pada mahasiswa adalah kebiasaan olahraga dengan $\mathrm{p} \quad$ value $=0,033 \quad(\mathrm{p}>0,05)$. Kebugaran jasmani dan kemampuan fisik dipengaruhi oleh kebiasaan olahraga karena olahraga melatih kerja fungsifungsi otot sehingga keluhan otot lebih jarang terjadi. Kebiasaan berolahraga dapat meningkatkan kemampuan kontraksi otot. Buruknya tingkat kelenturan (tonus) otot atau kurangnya olahraga dapat menyebabkan nyeri tulang punggung. Otot yang lemah terutama pada daerah perut tidak mampu menyokong punggung secara maksimal.

Latihan teratur dapat meningkatkan kekuatan dan fleksibilitas otot punggung, beban akan terdistribusi secara merata dan mengurangi beban hanya pada tulang belakang.

Pada penelitian ini diperoleh hasil bahwa lama duduk tidak mempunyai hubungan yang signifikan terhadap LBP dengan $\mathrm{p}$ value 0,280 . Penelitian ini sesuai dengan penelitian yang dilakukan oleh Lestari (2013) yaitu tidak ada hubungan antara lama duduk dengan keluhan subjektif nyeri pinggang dengan $\mathrm{p}$ value 0,324 .

Semakin lama seseorang duduk maka ketegangan otot dan keregangan ligamentum khususnya ligamentum longitudinalis posterior makin bertambah. Sebagaimana diketahui ligamentum longitudinalis posterior memiliki lapisan 
paling tipis setinggi L2- L5. Keadaan ini mengakibatkan daerah tersebut lebih sering terjadi gangguan. Namun demikian kaitan antara pekerjaan dan terjadinya NPB sangat kompleks karena melibatkan banyak struktur, elemen dari vertebra lumbalis. Vertebra lumbalis memiliki saraf sensoris sehingga mempunyai potensi untuk menimbulkan rasa nyeri.

Hasil penelitian ini menunjukkan bahwa terdapat hubungan yang signifikan antara berdiri dengan terjadinya Low Back Pain dengan $\mathrm{p}$ value $0,046(\mathrm{p}<0.05)$.

Posisi berdiri merupakan sikap kerja dengan posisi tulang belakang vertikal dan berat badan tertumpu secara seimbang pada dua kaki. Bekerja dengan posisi berdiri terus menerus sangat mungkin akan terjadi penumpukan darah dan berbagai cairan tubuh pada kaki. Sikap kerja berdiri dapat menimbulkan keluhan subjektif dan juga kelelahan bila sikap kerja ini tidak dilakukan bergantian dengan sikap kerja duduk.

Berat tubuh manusia akan ditopang oleh satu ataupun kedua kaki ketika melakukan posisi berdiri. Aliran beban berat tubuh mengalir pada kedua kaki menuju tanah. Hal ini disebabkan oleh faktor gaya gravitasi bumi. Kestabilan tubuh ketika posisi berdiri dipengaruhi posisi kedua kaki. Kaki yang sejajar lurus dengan jarak sesuai dengan tulang pinggul akan menjaga tubuh dari tergelincir. Selain itu perlu menjaga kelurusan antara anggota bagian atas dengan anggota bagian bawah.

Beban statis, penekanan pada jaringan lunak dan pembekuan pada vena dapat menyebabkan fatique, oleh sebab itu perlu adanya pergerakan dalam postur berdiri seperti berjalan-jalan atau bergerak dalam waktu yang singkat sebagai relaksasi agar aliran darah ke kaki tetap aktif.

Pada penelitian ini menunjukkan bahwa terdapat hubungan yang signifikan antara mengangkat dengan Low Back Pain dengan $\mathrm{p}$ value 0,027. Mengangkat merupakan salah satu pekerjaan pengangkatan beban manual material handling $(\mathrm{MMH})$ selain aktivitas memutar, membengkokkan, meraih, menurunkan, mendorong, menarik, membawa dan membalik yang dilakukan oleh pekerja dengan tujuan untuk memindahkan beban tersebut dari suatu lokasi asal menuju suatu lokasi tujuan tertentu.

Jika tubuh manusia mengangkat suatu beban, maka seluruh tubuh akan mengalami semacam ketegangan. Otot tubuh pada dasarnya berfungsi untuk menegakkan tubuh manusia dan jika otot ini diberi beban tambahan maka otot tubuh akan menegang dan pembuluh darah mengecil, akibatnya orang tersebut akan merasa letih. Ketegangan yang diderita otot tubuh akan semakin berat jika beban yang diterima semakin berat dan terjadi berulang (repetitive) serta cara pengangkatan yang tidak benar.

Dari hasil penelitian ini didapatkan stress merupakan salah satu faktor penentu Low Back Pain dengan tingkat kemaknaan $p$ value $=0,008$. Stress atau cemas dapat menyebabkan nyeri. Otot menjadi tegang sehingga mengakibatkan nyeri kuduk, kepala, atau punggung. Rahang yang dikencangkan atau gigi yang digertakan dapat menyebabkan nyeri pada muka. Kecemasan terlebih bila menahun dapat menurunkan nilai ambang nyeri, sehingga orang itu mengalami rasa nyeri yang lebih hebat, seperti pada penyakit menahun dengan nyeri, umpamanya kanker. Kecemasan dapat memperkuat 
rasa nyeri dan juga bila perhatian difokuskan pada sensasi-sensasi yang biasanya tidak dianggap nyeri seperti prestise, rasa gatal dan bahkan denyutan jantung atau gerakan usus.

Hasil penelitian ini ditunjang oleh Lincon, kepustakaan yang melaporkan stress berkontribusi pada nyeri pinggang. Lincon menyimpulkan dari hasil telaah sistematis bahwa faktor psikologi kerja mempunyai peran yang bermakna dalam masalah nyeri pinggang di masa mendatang. Faktor psikologi kerja yang berperan antara lain adalah kepuasan kerja, tugas yang monoton, dan stres. Gangguan psikologi pada pasien nyeri pinggang sukar diketahui dengan pasti kapan terjadinya. Gangguan ini dapat timbul sebelum terjadi nyeri pinggang atau sesudahnya. Gangguan psikologi yang terjadi setelah timbul nyeri pinggang dapat merupakan respons akibat kelainan fisik yang ada.

\section{KESIMPULAN DAN SARAN}

Berdasarkan analisis yang telah dilakukan, kesimpulan dari penelitian ini adalah prevalensi Low Back Pain pada mahasiswa jurusan Ortotik Prostetik Politeknik Kesehatan Surakarta adalah $32,2 \%$. Faktor risiko yang ditemukan dalam penelitian ini adalah jenis kelamin, indeks massat tubuh (IMT), kebiasaan olahraga, lama duduk, lama berdiri, kebiasaan mengangkat, dan stress. Faktor risiko yang paling berperan secara signifikan untuk terjadinya Low Back Pain pada mahasiswa jurusan Ortotik Prostetik Politeknik Kesehatan Surakarta adalah kebiasaan olahraga, lama berdiri, kebiasaan mengangkat dan stress. Dari hasil penelitian ini direkomendasikan bagi mahasiswa jurusan Ortotik Prostetik untuk mengadakan kegiatan olahraga secara rutin untuk pencegahan terhadap keluhan Low Back Pain, mengurangi intensitas berdiri yang terlalu lama dengan cara mengganti posisinya dengan duduk dan atau pergerakan lain seperti berjalanjalan, menghindari mengangkat benda kerja yang cukup berat yang mengerahkan tenaga yang berlebihan, menghindari perasaan cemas dan stress selama masa perkuliahan dengan cara selalu positive thinking dan terbuka dalam menerima pembelajaran, dan memperbanyak istirahat atau melakukan peregangan otot, terutama pada saat pembelajaran praktik. Bagi peneliti selanjutnya diharapkan dapat melakukan penelitian lebih lanjut dengan desain penelitian yang lebih kuat dengan analisis multivariat agar hasil yang didapatkan lebih signifikan dan meminimalisasi hasil yang bias.

\section{DAFTAR RUJUKAN}

Dachlan, Leo Muchamad, 2009; Pengaruh Back Exercise pada Nyeri Punggung Bawah. Universitas Sebelas Maret, Surakarta, hal 1-2 dan 47.

Huldani, 2012; Nyeri Punggung. Universitas Lambung Mangkurat, Banjarmasin.

Septiawan, Heru, 2013; Faktor yang Berhubungan dengan Keluhan Nyeri Punggung Bawah pada Pekerja Bangunan di PT Mikroland Property Development Semarang Tahun 2012. Universitas Negeri Semarang, Semarang, hal. 2.

Tana, L., et al, 2011; Determinan Nyeri Pinggang pada Tenaga Paramedis di Beberapa Rumah Sakit di Jakarta. Pusat Teknologi Terapan Kesehatan dan Epidemiologi Klinik Badan Penelitian dan 
Pengembangan Kesehatan, Kementrian Kesehatan Republik Indonesia, Jakarta.

Wibowo, G.A., 2012; Hubungan Tingkat Kecemasan dengan Intensitas Nyeri Pada Penderita Nyeri Punggung Bawah (Low Back Pain) di Poli Saraf RSUD Banyumas. Fakultas Kedokteran Universitas Muhammadiyah Surakarta, Surakarta.

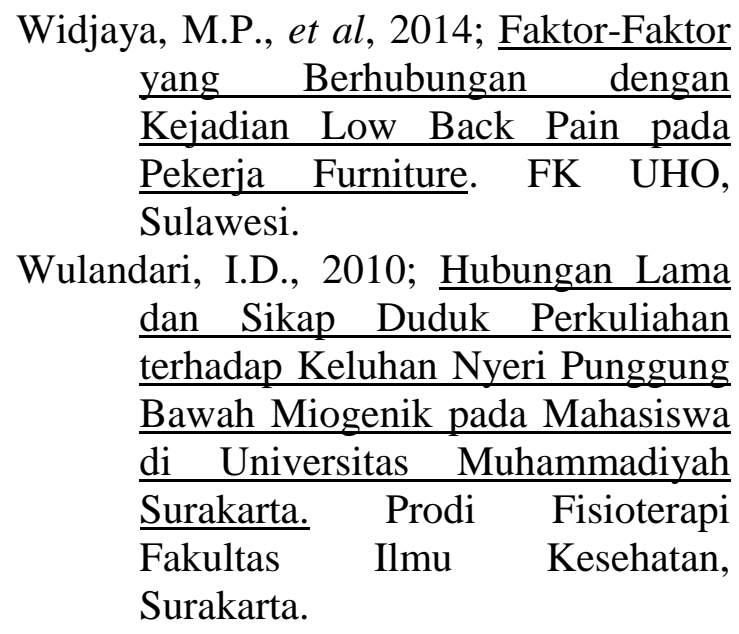

Widjaya, M.P., et al, 2014; Faktor-Faktor Kejadian Low Back Pain pada Pekerja Furniture. FK UHO, dan Sikap Duduk Perkuliahan terhadap Keluhan Nyeri Punggung Bawah Miogenik pada Mahasiswa di Universitas Muhammadiyah Fakultas Ilmu Kesehatan, Surakarta. 